\title{
DEZVOLTAREA FITOPLANCTONULUI FLUVIULUI NISTRU ȘI LACULUI DE ACUMULARE DUBĂSARI ÎN CONDIṬIILE IMPACTULUI FACTORILOR NATURALI ȘI ANTROPICI
}

\section{Laurenția Ungureanu, Daria Tumanova, Grigore Ungureanu}

Institutul de Zoologie, e-mail: ungur02laura@yahoo.com, dariatumanova@gmail.com

https://doi.org/10.53937/9789975151979.07

\section{Rezumat}

Articolul prezintă rezultatele cercetărilor privind indicatorii calitativi și cantitiativi ai fitoplanctonului în fluviul Nistru și lacul Dubăsari în Republica Moldova în 2020. În compoziția fitoplanctonului din fluviul Nistru au fost identificate 64 de specii, iar în lacul Dubăsari - 56 de specii. Efectivul fitoplanctonului s-a modificat în limitele 0,39-16,99 mln. cel/l, cu o biomasă de 0,7-17,19 $\mathrm{g} / \mathrm{m}^{3}$ în fl. Nistru și 3,47-14,83 mln. cel /l, cu o biomasă de 4,76-11,29 $\mathrm{g} / \mathrm{m}^{3}$ - în lacul Dubăsari. Valorile indicilor saprobici, estimate pe baza speciilor indicatoare din compoziția fitoplanctonului, care sunt tipic $\beta$-mezosaprobe în proporție de $60 \%$, confirmă următoarele: calitatea apei fl. Nistru și a lacului Dubăsari în perioada anului 2020 a fost satisfăcătoare pentru dezvoltarea fitoplanctonului și a fost atribuită, în temei, claselor de calitate II-III (bună-moderat poluată).

Cuvinte-cheie: fitoplancton, specii indicatoare, calitate a apei, troficitate, fluviul Nistru, acumularea Dubăsari

\section{INTRODUCERE}

Modificarea stării mediului acvatic sub influența factorilor naturali și antropici influențează considerabil structura și funcționarea organismelor acvatice și este una dintre cele mai stringente probleme globale de mediu ale societății moderne. Poluarea apei cu diferiți compuși chimici provoacă eutrofizarea excesivă a ecosistemelor acvatice. Republica Moldova are o cantitate relativ mică de ape de suprafață, iar gradul de asigurare cu apă potabilă este scăzut din cauza poluării intensive a resurselor de apă [3, 5].

Algele ca parte componentă a ecosistemelor acvatice fluviale și lacustre, se află în relații directe sau indirecte cu celelalte componente și funcționează fiind influențate de particularitățile hidrologice, hidrochimice și hidrobiologice care creează anumite condiții abiotice și biotice pentru dezvoltarea lui. Succesiunile sezoniere ale fitoplanctonului sunt unul dintre indicatorii de bază

\begin{abstract}
The article presents the results of study of qualitative and quantitative indicators of phytoplankton of the Dniester River within the Republic of Moldova and Dubasari reservoir in 2020. In phytoplankton compositions of the Dniester River were identified 64 species, Dubasari Lake - 56 species. The numbers of phytoplankton changed within the limits 0,39 to $16,99 \mathrm{mln}$. cel/l with biomass $0,7-17,19 \mathrm{~g} / \mathrm{m}^{3}$ in Dniester River and in Dubasari Lake - 3,47-14,83 $\mathrm{mln}$. cel/l with biomass $4,76-11,29 \mathrm{~g} / \mathrm{m}^{3}$. The values of saprobic indexes, estimated on the basis of species-indicators from phytoplankton composition, which are in proportion of $60 \%$ typically $\beta$-mezosaprobic, confirm the following: the water quality of Dniester River and Dubasari Lake in the period of 2020 year was satisfactory for the development of phytoplankton and was attributed mainly to II-III (good-moderately polluted) quality classes.
\end{abstract}

Keywords: phytoplankton, species-indicators, water quality, trophicity, Dniester River, Dubasari reservoir

care caracterizează stabilitatea comunităților de alge și gradul lor de adaptare la condițiile variabile ale mediului acvatic. Algele planctonice sunt foarte sensibile la modificările parametrilor fizici și chimici ai apei, și pot servi ca indicatori ai poluării apei, fiind folosite în activităţile de evaluare a gradului de contaminare cu poluanți și a calităţii apei. Fitoplanctonul reacționează rapid la schimbările condițiilor ecologice, iar productivitatea lui determină nivelul trofic al ecosistemelor acvatice și caracterizează starea lui sanitară [3].

\section{MATERIALE ȘI METODE}

Probele de fitoplancton au fost colectate sezonier din fl. Nistru și lacul de acumulare Dubăsari în decursul anului 2020 în cadrul cercetărilor Laboratorului de Hidrobiologie și Ecotoxicologie al Institutului de Zoologie. Colectarea și procesarea probelor a fost efectuată conform metode- 
lor unificate de colectare și prelucrare a probelor hidrobiologice de teren și experimentale [1, 2, 4]. Speciile de alge planctonice au fost identificate la microscopul MICMED/2 (LOMO), dotat cu cameră digitală, consultând determinatoarele în vigoare și alte materiale de referință. Analiza saprobiologică a fost bazată pe lista speciilor de alge indicatoare ale calității apei $[4,5]$. Pentru estimarea gradului de troficitate al fl. Nistru și al lacului de acumulare Dubăsari au fost utilizate valorile sezoniere ale biomasei fitoplanctonului $[1,2]$. Pe parcursul anului 2020 au fost colectate și analizate probe de fitoplancton prelevate la statiile relevante în sectorul mijlociu și sectorul inferior al fluviului Nistru.

\section{REZULTATE ȘI DISCUȚII}

A fost stabilită diversitatea taxonomică și parametrii cantitativi ai comunităților de fitoplancton în fl. Nistru și lacului de acumulare Dubăsari. În fl. Nistru fitoplanctonul a fost reprezentat de 64 specii și varietăti de alge planctonice care se referă la 5 grupe taxonomice: Cyanophyta $-7, B a-$ cillariophyta - 35, Pyrrophyta-3, Euglenophyta - 3, Chlorophyta - 16. Cele mai răspândite specii au fost: Oscillatoria lacustris, Cocconeis placentula, Cyclotella kuetzingiana, Gomphonema olivaceum, Navicula cryptocephala, Nitzschia sigmoidea, Synedra acus, Monoraphidium contortum, Scenedesmus quadricauda. $\mathrm{N}$-au fost atestate specii din grupa Chrysophyta și Xanthophyta care au fost atestate în anii precedenți. A fost stabilit ca în perioada de iarnă au predominat speciile din grupele de alge $B a$ cillariophyta și Pyrrophyta, iar în decursul primăverii s-au dezvoltat și speciile de alge din grupele Cyanophyta, Euglenophyta și Chlorophyta.

Efectivul numeric al fitoplanctonului fl. Nistru în anul 2020 a variat în limitele 0,39-5,22 mln cel./l, cu biomasa 1,07-5,4 g/m $\mathrm{m}^{3}$ în perioada de iarnă-primăvară (Fig.1.). Iarna au fost stabilite valori mai ridicate ale efectivului și biomasei la stația Soroca, în care a fost atestată dezvoltarea algelor din grupa Bacillariophyta. Pe parcursul primăverii odată cu creșterea temperaturii s-au majorat valorile efectivului și biomasei algelor planctonice în ambele sectoare ale fluviului Nistru.

În perioada de vară valorile efectivului și biomasei au variat în limite destul de mari situându-se între 2,99-16,99 mln cel./1 și 3,57-17,19 g/ $\mathrm{m}^{3}$, respectiv. Valori mai ridicate ale efectivului au fost atestate la stația Palanca cu ponderea speciilor din grupa Cyanophyta (6,86 mln cel./l): Aphanizomenon flos-aquae, Oscillatoria lacustris,
Oscillatoria planctonica, Synechocystis aquatilis și a celor din grupa Chlorophyta (6,62 mln cel./l): Aktinastrum hantzschii, Monoraphidium contortum, Scenedesmus quadricauda. În formarea biomasei au participat preponderent speciile de alge din grupa Bacillariophyta $\left(6,38 \mathrm{~g} / \mathrm{m}^{3}\right)$ : Cocconeis placentula, Diatoma vulgare v.vulgare, Nitzschia sigmoidea, Synedra ulna și Pyrrophyta $\left(4,96 \mathrm{~g} / \mathrm{m}^{3}\right)$ : Glenodinium gymnodinium.

În perioada de toamnă valorile efectivului au variat în limite 1,08-6,57 mln cel./l, iar ale biomasei între $0,7-3,81 \mathrm{~g} / \mathrm{m}^{3}$, cu ponderea algelor din grupa Bacillariophyta la stațiile Otaci și Palanca. Modificările regimului hidrologic și hidrochimic al fl Nistru în rezultatul construcțiilor hidrotehnice, deversărilor de ape reziduale și aportului scurgerilor de substanțe nutritive și toxice de pe teritoriile adiacente provoacă modificări semnificative în componența algoflorei. Ele sunt relevant reflectate în modificările ponderii diferitor grupe taxonomice în structura comunităților de alge planctonice, în succesiunile sezoniere și multianuale ale efectivului și biomasei acestora.

Pe parcursul investigațiilor 2020 în sectorul mijlociu al fl. Nistru de la st. Naslavcea până la st. Camenca valorile biomasei au variat în limite 1,07$6,96 \mathrm{~g} / \mathrm{m}^{3}$ fiind în dependență de anotimp și ponderea în componența fitoplanctonului a unei sau altei grupe de alge planctonice. Cele mai mari valori au fost înregistrate vara la stația Camenca, ce se referă la categoria de troficitate „eutrof” uneori "mezotrof". Conform valorilor biomasei fitoplanctonului $\left(0,7-17,19 \mathrm{~g} / \mathrm{m}^{3}\right)$ sectorul inferior al fl. Nistru (de la Vadul-lui-Vodă până la Palanca) se referă la categoria de troficitate „eutrof” uneori “mezotrof". Cele mai ridicate valori ale biomasei au fost atestate primăvara la st. Palanca. A fost stabilită tendința de micşorare a biomasei fitoplanctonului din primăvară spre toamnă. Pe tot cursul râului valorile biomasei n-au depășit limitele categoriei de troficitate „eutrof” (Fig.1.).

În anul 2020 în lacul de acumulare Dubăsari au fost identificate 56 specii de alge planctonice, care

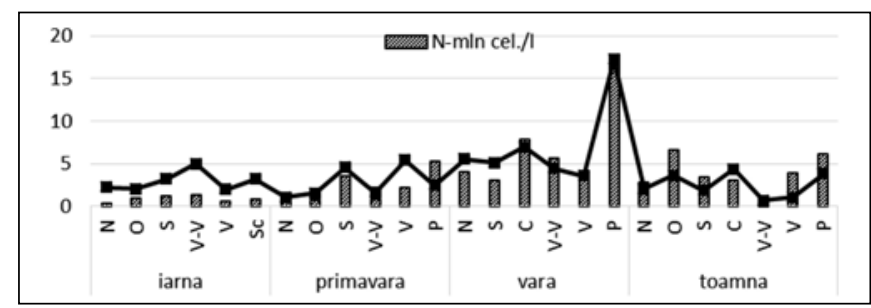

Fig. 1. Dinamica efectivului (N- mln cel./l) şi biomasei $\left(\mathrm{B}-\mathrm{g} / \mathrm{m}^{3}\right)$ fitoplanctonului fl. Nistru (N-Naslavcea, O-Otaci, S-Soroca, C-Camenca, V-V-Vadul-lui-Voda, V-Varnița, Sc-Sucleia, P-Palanca) în 2020. 
se referă la 5 grupe taxonomice: Cyanophyta-3, Bacillariophyta-32, Euglenophyta-5, Pyrrophyta-4, Chlorophyta-12. Cele mai frecvent întâlnite specii au fost: Oscillatoria lacustris, Synechocystis aquatilis, Cyclotella Kuetzingiana., Cymatopleura solea, Gomphonema olivaceum, Navicula gracilis, Navicula cryptocephala, Nitzschia acicularis, Nitzschia sigmoidea, Synedra ulna, Ceratium hirundinella, Euglena polymorpha, Monoraphidium contortum, Scenedesmus quadricauda.

Baza floristica a fitoplanctonului lacului de acumulare Dubăsari a fost constituită din reprezentanții filumurilor Bacillariophyta și Cyanophyta. $\mathrm{N}$-au fost atestate specii din grupa Chrysophyta, care se dezvoltau în lac în anii precedenți. Cea mai ridicată diversitate a fitoplanctonului a fost atestată în sectorul mijlociu al lacului Dubăsari. Dezvoltarea fitoplanctonului în lacul de acumulare Dubăsari, în special în sectorul superior al acestuia, depinde în mare măsură de conținutul substanțelor nutritive și a celor poluante provenite din sectorul mijlociu al fl. Nistru.

Valorile efectivului fitoplanctonului lacului de acumulare Dubăsari în anul 2020 au variat în limitele 3,47-14,83 mln cel./1 cu biomasa 4,76-11,29 $\mathrm{g} / \mathrm{m}^{3}$. Valorile ridicate ale efectivului fitoplanctonului au fost atestate în sectorul inferior al lacului, fiind cauzate de dezvoltarea algelor din grupa Cyanophyta- 6,06 mln cel./1, cu ponderea speciei Synechocystis aquatilis. Valorile ridicate ale biomasei au fost înregistrate în perioada vernală în sectorul inferior al lacului, fiind cauzate de dezvoltarea intensivă a speciilor cu masa individuală mare din grupele Bacillariophyta - $5,07 \mathrm{~g} / \mathrm{m}^{3}$ și Pyrrophyta $-4,07 \mathrm{~g} / \mathrm{m}^{3}$. După valorile biomasei algelor planctonice apa lacului de acumulare Dubăsari se atribuie categoriei de troficitate „eutrof”.
Din numărul total de 64 de specii de alge, care au fost identificate în anul 2020 în fl. Nistru, 42 sunt specii indicatoare ale saprobității apei. Cele mai multe dintre ele, $57 \%$ sunt specii $\beta$-mesosaprobe, din care mai frecvent întâlnite au fost: Aphanizomenon flos-aquae, Cocconeis placentula, Cyclotella kuetzingiana, Diatoma vulgare v.vulgare, Gomphonema olivaceum, Gyrosigma acuminatum, Nitzschia sigmoidea, Synedra acus, Synedra ulna, Trachelomonas hispida, Scenedesmus quadricauda. $14 \%$ au constituit speciile a -mesosaprobe la care se referă: Navicula cryptocephala, Nitzschia acicularis, Nitzschia palea, Hantzschia amphioxis, Euglena polymorpha. 14\% se referă la speciile o-b mesosaprobe: Anabaena spiroides, Amphora ovalis, Asterionella formosa, Melosira italica, Crucigenia tetrapedia . Speciile b-a-mesosaprobe, care constiuie $7 \%$, au fost reprezentate de algele: Cymatopleura solea, Navicula cincta, Navicula hungarica v.capitata. Specii b-o-mesosaprobe (Navicula gracilis), a-b-mesosaprobe (Cyclotella meneghiniana) și o-olosaprobe (Gleocapsa turgida) au constituit circa $8 \%$ (Fig. 2.).

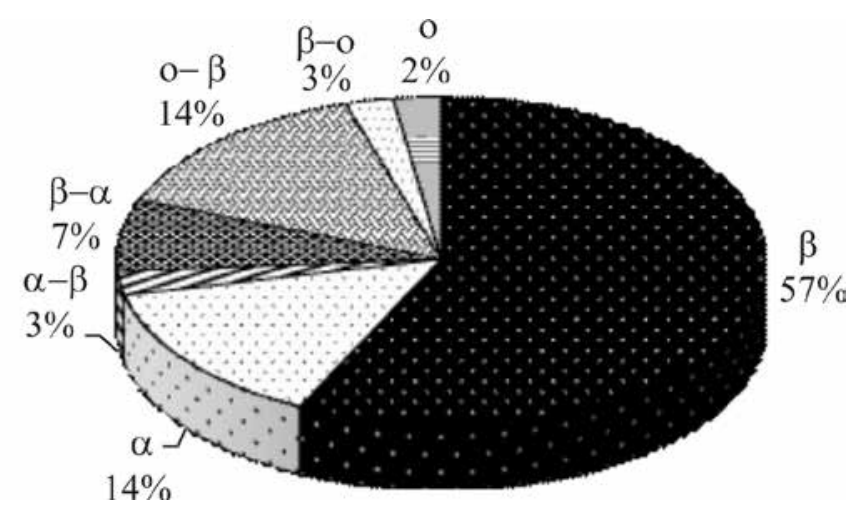

Fig. 2. Distribuția speciilor indicatoare din componența fitoplanctonului fl. Nistru în zonele de saprobitate în 2020.

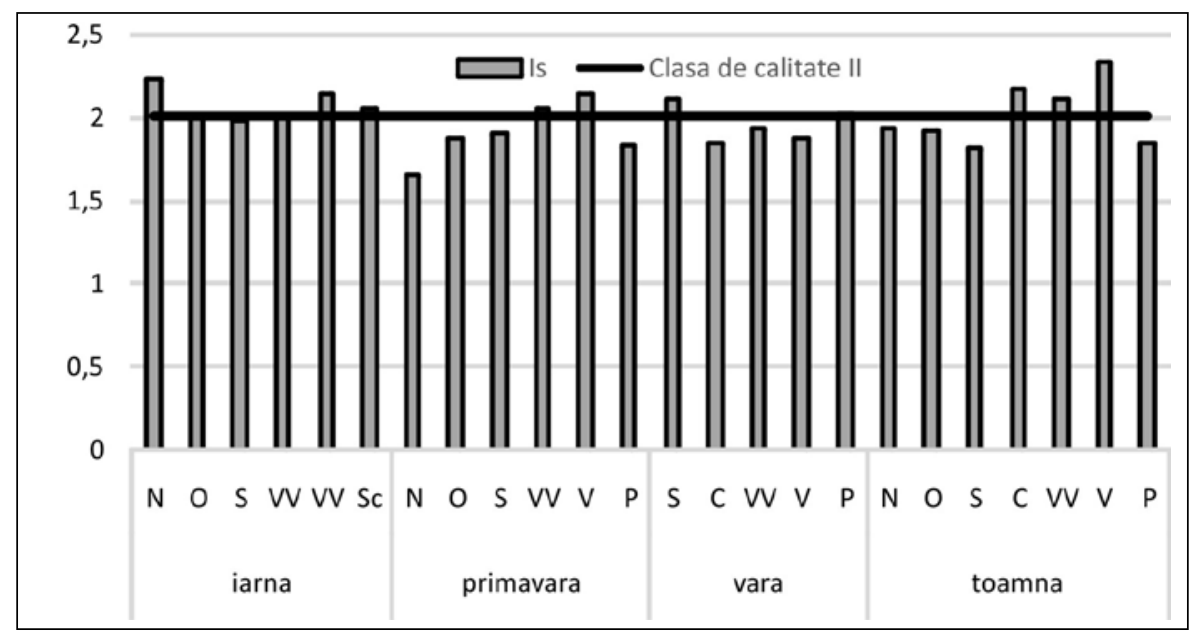

Fig. 3. Variațiile valorilor indicelui saprobităţii în fl. Nistru(N-Naslavcea, O-Otaci, S-Soroca, C-Camenca, V-V-Vadul-lui-Voda, V-Varnița, Sc-Sucleia, P-Palanca) în anul 2020. 
În anul 2020 au fost înregistrate fluctuații mari ale indicelui saprobic al fluviului Nistru în aspect sezonier și în diferite sectoare ale acestuia. Analiza valorilor indicelui de saprobitate al sectorului mijlociu și inferior al fl. Nistru ne-a permis să constatăm fluctuații semnificative ale nivelului de poluare. În fl. Nistru au predominat speciile cu preferență la zona $\beta$-mesosaprobă. Valorile indicelui saprobic au variat în perioada de iarnă în limitele $1,98-2,23$, primăvara în limitele $1,65-2,15$, vara între 1,85-2,11, iar toamna între 1,82-2,34. Valorile indicelui saprobic al fl. Nistru se încadrează în limitele claselor calității apei II-a și III-a (bună-poluată moderat) (Fig.3.).

Pe parcursul anului 2020 în lacul Dubăsari au fost identificate 56 specii de alge planctonice dintre care 37 sunt specii indicatoare ale saprobității apei. Speciile $\beta$-mesosaprobe au constituit $62 \%$ din totalul de specii indicatoare.

Valorile indicelui saprobic au variat în limitele $1,86-2,16$ și se încadrează în limitele zonei $\beta$-mezosaprobe și claselor calității apei II-a și III-a calificând apa lacului de acumulare Dubăsari ca fiind bună - poluată moderat. Apariția mai frecventă a euglenofitelor în lacul de acumulare Dubăsari, atestă conținutul mai înalt al substanțelor organice și o poluare mai pronunțată.

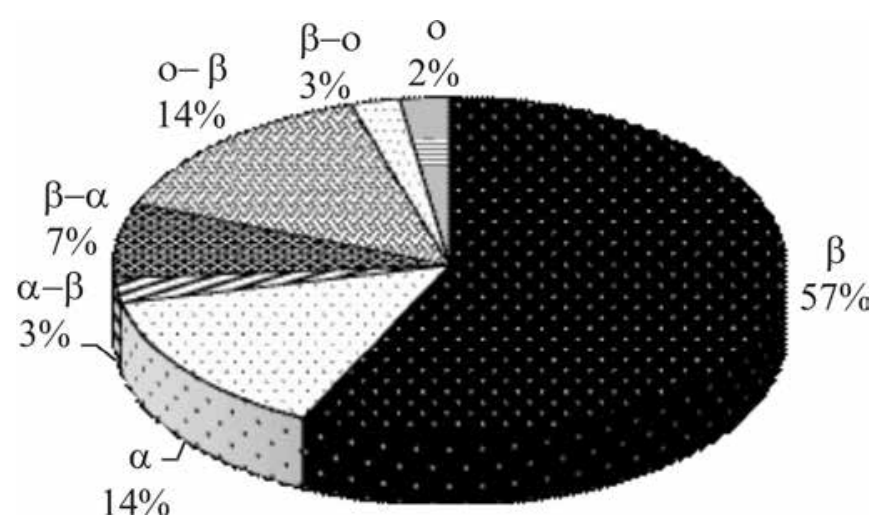

Fig. 4. Distribuția speciilor indicatoare din componența fitoplanctonului lacului de acumulare Dubăsari în zonele de saprobitate în 2020.

\section{CONCLUZII}

1. Baza floristica a fitoplanctonului fluviului Nistru și lacului de acumulare Dubăsari a fost constituită din 5 grupe taxonomice: Cyanophyta, Bacillariophyta, Pyrrophyta, Euglenophyta, Chlorophyta.

2. În anul 2020 valorile efectivului fitoplanctonului fl. Nistru au variat în limitele 0,39-16,99 mln cel./1, cu biomasa 0,7-17,19 g/m $\mathrm{m}^{3}$, iar în lacul de acumulare Dubăsari au variat în limitele 3,47$14,83 \mathrm{mln}$ cel./1 cu biomasa 4,76-11,29 g/ $\mathrm{m}^{3}$.

3. Conform valorilor biomasei fitoplanctonului al fl. Nistru și lacul de acumulare Dubăsari pot fi atribuite categoriei ecosistemelor „eutrofe” periodic "mezotrofe”.

4. În ecosistemele studiate în componența fitoplanctonului predomină speciile $\beta$-mezosaprobe, iar după valorile indicelui saprobic al fitoplanctonului calitatea apei atât în fl. Nistru cât și în lacul de acumulare Dubăsari se atribuie claselor II-III (bună-poluată moderat).

5. Formarea calității apei în fluviul Nistru depinde în mare măsură de condițiile de reglare a debitului apei, de cantitatea și natura poluanților proveniți din diferite localități situate pe cursul acestuia sau aduse de afluenții Răut și Bâc.

Investigațiile au fost realizate în cadrul proiectului 20.80009.7007.06 "Determinarea schimbărilor mediului acvatic, evaluarea migrației și impactului poluanților, stabilirea legităților funcționării hidrobiocenozelor și prevenirea consecințelor nefaste asupra ecosistemelor”, finanțat de Agenția Națională pentru Cercetare și Dezvoltare din Republica Moldova.

\section{REFERINTTE}

1. UNGUREANU L., TUMANOVA D. Sampling of fitoplankton. In: Ghid de prelivare a probelor hidrochimice si hidrobiologice $=$ Hydrochemical and hydrobiological sampling guidance. Chișinău 2015; p.12-14

2. UNGUREANU L., TUMANOVA D., UNGUREANU G. Fitoplancton. Producția primară a fitoplanctonului și destrucția materiei organice. În:Îndrumar metodic: Monitoringul calității apei și evaluarea stării ecologice a ecosistemelor acvatice./Acad. de Stiiințe a Moldovei, Inst.de Zoologie, Univ. Acad. de Științe a Moldovei Chișinău 2015; p.41-45

3. UNGUREANU L., TUMANOVA D. Calitatea apei ecosistemelor acvatice principale ale bazinului fluviului Nistru. În: Buletinul Academiei de Științe a Moldovei. Științele vieții. Chișinău, 2010, N 3 (312), p. 101 - 110.

4. Regulament cu privire la cerințele de calitate a mediului pentru apele de suprafață. Anexa 1. publicat: 22.11.2013 în Monitorul Oficial Nr.262267, art. Nr.1006, 2013, p. 32-39.

5. ВАССЕР С.П. и др. Водоросли. Справочник. Киев: Наукова Думка, 1989. 60 с. 